and it is possible that lacrimation might occur under the same circumstances. The phenomenon of "crocodile tears," in which the normal flow of saliva at meal times is, accompanied by lacrimation, is due to injury to the chorda tympani branch of the seventh cranial nerve. Bilateral salivation and lacrimation in an elderly man would suggest either paralysis agitans or vascular degenerative changes in the cortical vessels. Presuming one of these two conditions was responsible, treatment should be by atropine or stramonium, pushed, if necessary, to the limit of tolerance as shown by disturbance of ocular accommodation.

\section{Novocain Injections}

Q.-It is very easy to pierce a vein with the fine needle used by dentists. The anaesthetic solution usually contains $3 \%$ novocain and a variable amount of adrenaline (about $0.00002 \mathrm{gr}$. per c.cm. or more). What are the dangers of direct injection into the blood stream? How much is due to novocain and how much to the adrenaline content?

A.- The dangers of direct injection of the anaesthetic solution into the vascular system are not great. It is unlikely that enough will enter the blood stream to produce noteworthy toxic effects unless the patient has a marked idiosyncrasy to one or other of the drugs. Intravenous administration of adrenaline is a dangerous procedure, and it is possible that the tachycardia and other systemic effects may be due to small amounts of adrenaline getting into the blood stream. It is more likely, however, that these unpleasant effects are the results of emotional disturbance causing an increase in the secretion of the adrenal medulla.

\section{Labyrinthine Vertigo}

Q.-Is labyrinthine vertigo always associated with deafuess, or can it be associated in mild early cases with hyperacusis? I find the latter vaguely referred to by Wheeler and Jack. In a case of recurrent vertigo with nausea and vomiting and slight nystagmus, does the presence of hyperacusis rather than deafness rule out labyrinthine disturbance?

A.-Hyperacusis, or more properly dysacusis, occurs after head injuries, and also in functional conditions. Labyrinthine vertigo is always associated with some deafness of the affected ear, and it is possible that the case described is of a functional nature.

\section{A Dificult Arthritic Case}

Q.-A man aged 59, with generalized rheumatoid arthritis, came to me last year with his right leg bent and the knee inflamed. I applied weight extension and have now put it at rest straight for 9 months. This knee now appears normal, but he has not been able to use his caliper because the other knee is inflamed. Is it safe for him to use-i.e., stand on-the right leg now, or will the disease become active again if he attempts to stand on it?

A.-It is difficult to give an opinion on this case without further details, such as the sedimentation rate as an indication of the existence of an active infective process, and radiographs of the affected joints to show the actual condition of the articular surfaces and the density of the bones themselves. Assuming, however, that the sedimentation rate is normal or nearly so, it is likely that standing for short periods would not have any ill effects, or even walking for short distances in the house. The occurrence of inflammation, while suggestive of active disease, may be due only to the trauma of excessive use on damaged synovial tissues.

\section{Arterial Disease}

Q.-Is the age of 38 too young to find a condition of arteriosclerosis, and can an arteriosclerosis occur in the mesenteric vessels without there necessarily being evidence of its presence in the peripheral superficial vessels?

A.-Severe arterial disease, such as atheroma, may sometimes be found at a much earlier age, particularly in the coronary arteries. Atheroma would be the most likely form of arterial disease in th. mesenteric artery. The peripheral superficial arteries give no indication of the presence of atheroma in the internal arteries. Polyarteritis nodosa may occur in such vessels as the mesenteric artery: and superficial arteries-e.g., the temporal-may suggest its presence

\section{INCOME TAX}

\section{Deduction of Tax from Salary}

E. G. is in receipt of a pension, and also of remuneration from an appointment under a local authority. He is unable to reconcile the amounts of tax deducted with his circumstances.

${ }_{*}^{*}$ The difficulty probably arises from the fact that while the total amount of tax to be paid depends on the total income and total allowances, as a matter of law each separate source of income requires to be dealt with separately. In the circumstances we suggest that a personal discussion at the office of the inspector of taxes, preferably by appointment, is most likely to clear up the matter.

\section{LETTERS, NOTES, ETC. \\ Answers Supplemented}

Di. W. St. Aubyn Hubbard (Falmouth) writes: In the B.M.J. of Sept. 16 (p. 390) I was surprised to find no mention of liq. ferri perchlor. fort. as a paint for the palliative treatment of ingrowing toe-nail. Since seeing it recommended in the Journal some years ago I have often used it with gratifying results. The paint is applied to the painful sulcus at frequent intervals, the nail is allowed to grow until the whole width can be cut with a concave edge instead of the usual convex, and tight shoes or tight shrunken socks carefully avoided. Some, who dread the small radical operation, appear to carry on thus for years.

The answer given to the seasickness question (Sept. 16, p. 391) also interested me, as there was no mention of bandaging. I have spent some years at sea and under severe weather conditions have suffered myself occasionally. In treating cases I have seldom found any need for drugs if only a wide belt is properly applied. I used to bind my abdomen from below upwards with a wide flannel bandage as tightly as possible, and, to increase the resulting support to the viscera, I used to pack down inside the bandage one of the monthly magazines sometimes. It was rather uncomfortable, perhaps, but that was far better than feeling seasick. The whole tip is to fix the viscera and blow the discomfort. One lady to whom I recommended this, who had been very seriously ill whenever she had had to make her frequent transatlantic crossings, and had always spent the whole time in her berth, told me that she was able to enjoy her subsequent voyages. Seeing that so many of our people have to make sea voyages in the Services just now, this simple method of dealing with mal-de-mer may be well worth recommending to them.

\section{Prefrontal Leucotomy}

Dr. Brian Kirman (St. Mary Cray, Kent) writes: The statement on prefrontal leucotomy and its performance on non-institutional patients (Nov. 11, p. 650) is, I think, liable to misinterpretation. We are informed, "Leucotomy should not be recommended where patients occupy professional or highly responsible executive posts if there is a reasonable chance of recovery without operation." Surely if any patient, whatever his occupation, has a reasonable chance of recovery without this hit-or-miss operation then he should not be operated on. Surely, in particular, it is important that holders of responsible operative, as distinct from executive, posts -e.g., engine-drivers-should not be given the " more irresponsible attitude to life" which may follow the operation of leucotomy. I find it difficult to believe that any patient can suffer from a depression so mild that he can continue outside a mental hospital and yet so severe and intractable that the drastic step of leucotomy is justified. Further, it will be admitted that the final decision in any case of mental disorder must be based on the patient's conduct rather than on his thought content. Particularly must this be so where the irrevocable step of leucotomy is contemplated. Yet is there not a grave risk that if the patient be not admitted to a properly staffed psychiatric unit inadequate and unreliable information as to conduct may lead to inaccurate assessment and prognosis? Finally, no mention is made in the answers which you publish of the legal complications that may develop as a result of an operation performed on a patient (though it be with his consent) on account of mental disorder, a patient who has not been admitted to any properly organized and approved psychiatric establishment. The value of this operation in non-institutional cases is not established. The harm which it can do if inexpertly advised is incalculable. Under these circumstances is it not desirable at least to limit its use to patients in recognized psychiatric establishments until some more definite assessments of its results have been made?

\section{Atmospheric Pressure and Rheumatism}

Dr. J. S. Archibald (British Columbia) writes: I have been looking over some back copies, and in your "Any Questions?" column for March 4, 1944 (p. 347) I see where you failed to give an answer for the variation in rheumatic pains under different weather conditions. I have read recently that the low atmospheric pressure just before a storm causes a swelling of the bodily tissues which irritates the nerves around an abnormal joint, the site of an old fracture, etc. When the rain comes the pressure rises, with disappearance of the pain.

The Ophthalmoscope in Examining the Tongue

Dr. R. D. LAWRENCE (London, W.1) writes: Lacking an ordinary torch and magnifying lens I recently used my ophthalmoscope with $\mathrm{a}+15 \mathrm{D}$. lens to inspect the papillae of a sore tongue. The good light and high magnification $(\times 18)$ give a most informative and gratifying view. Since then $I$ have used it to examine rashes and other skin lesions. Perhaps this suggestion may help others.

\section{Corrigendum}

There were two errors in the heading to the article on "Chronic Intracerebral Haematomata " by Mr. Rowbotham and Dr. Ogilvie published last week at page 146 . The second entry in the title should read: A. G. OGiLvie, M.D., M.R.C.P., Honorary Physician, Royal Victoria Infirmary, Newcastle upon Tyne. 